Clinic Emergency Preparedness Project and the development of the Clinic Emergency Preparedness Help Desk.

Connecticut's approach to health emergency preparedness at the CCHC-level has been to form links with other state and local partners in order to weave a tightly integrated network for disaster response. The $\mathrm{CCHCs}$ in Connecticut have focused on their strengths of providing culturally- and linguistically-appropriate medical and behavioral health care to populations that traditionally have been difficult to reach. One in 19 Connecticut residents utilize the services of a $\mathrm{CCHC}$ for their primary care. Of these patients, more than $40 \%$ have reported that they are best served in a language other than English.

Conclusions: California and Connecticut have taken different, but complementary, approaches to $\mathrm{CCHC}$ emergency preparedness, which have been tailored to the needs of each state.

Keywords: California; Connecticut; community; community clinic and health centers (CCHC); diverse; preparedness

Prebosp Disast Med 2005:20(5):s163-s164.

\section{A Decade of Petroleum Disasters in Nigeria}

Osazuwa Ogbegor, ${ }^{1}$ Edeaghe E. Ebikbamenor ${ }^{1,2}$

1. Save Accident Victims Association of Nigeria (SAVAN), Benin City, Edo State, Nigeria

2. Accident and Emergency Unit, University of Benin Teaching Hospital, Benin City, Edo State, Nigeria

Introduction: Nigeria, the sixth largest oil-producing nation in the Organization of the Petroleum Exporting Countries (OPEC), receives $95 \%$ of its foreign exchange from oil exports to the global market. As a result, disasters affecting the petroleum industry in have national significance.

Objective: This presentation describes emergencies and disasters that have affected Nigeria's petroleum industry over the past decade.

Methods: Descriptive information concerning these events was obtained through the authors' observations, anecdotal reports, and reports from local media and government, when available.

Results: Types of petroleum-related emergencies and disasters occurring in Nigeria in the past decade include pipeline explosions, kerosene explosions, and repeated militant attacks on oil installations. The Jesse oil pipeline explosion in 1998 killed $>1,000$ persons. Kerosene explosion disasters have occurred in Lagos, Benin, Abuja, and several other states. The impact of these events includes health damage (morbidity and mortality), environmental degradation, social damage, and economic damage (including loss of man-hours). Petroleum-related events are likely to recur in the next decade due to a lack of government sanctions for responsible parties, poor policy formulation, and continued poverty.
Conclusion: Petroleum-related emergencies and disasters have a large impact across all segments of Nigerian society. The social, economic, and environmental damage from these events likely has very exceeded the health damage to the first generation of victims.

Keywords: disaster; environment; explosions; health damage;

petroleum; Nigeria; Organization of the Petroleum Exporting

Countries (OPEC)

Prehosp Disast Med 2005;20(5):s164.

Regional Trends in Road Traffic Crashes in Ghana, 2002-2004: What Are the Implications?

Eseoghene Okparavero

\section{University of Ghana Medical School, Korle-BU, Accra, Ghana}

Introduction: The burden and pattern of injuries resulting from road traffic crashes (RTCs) in Africa are not well described.

Objective: This study describes the burden of RTCs in different regions of Ghana.

Methods: A retrospective study of RTC data in different regions of Ghana was performed. Data were collected from the National Road Safety Commission and analyzed using simple descriptive statistics.

Results: Certain regions, such as Greater Accra, were identified as having a relatively higher incidence of RTCs ("black spots"). Possible reasons for this higher incidence will be suggested during this presentation.

Conclusion: The government in Ghana should use this data to direct its RTC prevention and mitigation efforts. Keywords: Ghana; incidence; road traffic accidents Prebasp Disast Med 2005;20(5):s164.

Development and Evolution of a Collaborative Community-wide Mass Vaccination Program

Michael F. Parry, ${ }^{1}$ Jobnnie Lee, ${ }^{2}$ Edward McCormack ${ }^{3}$

1. Stamford Hospital, Stamford, Connecticut, USA and Columbia University College of Physicians and Surgeons, New York, New York USA

2. Department of Health, City of Stamford, Stamford, Connecticut USA

3. Stamford Hospital, Stamford, Connecticut USA

Introduction: During the winter of 1997-1998, the need to improve influenza vaccine delivery in Stamford, Connecticut became clear when high rates of respiratory illness led to emergency department overcrowding and a critical shortage of hospital beds.

Objective: This presentation describes the development and evolution of a collaborative, community-wide influenza vaccine program (IVP).

Methods: Descriptive information was obtained from observations and records associated with the IVP, including an electronic database of patient demographics and volume over six seasons in Stamford. 